\title{
AS FACES DE JANO BIFRONTE NO DIÁLOGO ENTRE TRAMAS E TENSÕES: \\ ENTREVISTA COM O PROF. DR. ADAIL SOBRAL
}

\begin{abstract}
Ederson Luís Silveira é mestrando em Linguística na Universidade Federal de Santa Catarina - UFSC; bolsista da Coordenadoria de Aperfeiçoamento de Pessoal de Nível Superior-CAPES; pós-graduando em Ontologia e Epistemologia pela AVM Faculdades Associadas e membro do Grupo de Estudos em Territorialidades da Infância e Formação Docente (FORMATE-GESTAR$\mathrm{UESB} / \mathrm{CNPq}$ ).

E-mail: ediliteratus@gmail.com
\end{abstract}

Jefferson Campos é professor da Faculdade Metropolitana de Maringá (UNIFAMMA), doutorando em Letras pela Universidade Estadual de Maringá (UEM) e membro do Grupo de Estudos em Análise do Discurso (GEDUEM-UEM/CNPq).

E-mail: jeffersoncampos@geduem.com.br

Sobre o entrevistado: Adail Sobral é professor adjunto do PPG Linguística Aplicada da UCPEL-RS e da graduação em Letras na mesma instituição. É doutor em Linguística Aplicada pela PUC-SP, mestre em Letras pela USP, especialista em Linguística pela Unicamp e graduado em Letras-Inglês pela UFBA. É tradutor de textos em inglês, francês, italiano, português e tem experiência na área de Linguística Aplicada, atuando principalmente nos seguintes temas: Gênero, Discurso, Dialogismo, Círculo de Bakhtin, Semiótica Geral e Greimasiana, Tradução e Interpretação. É organizador da obra Conversas com tradutores, publicado pela editora Parábola em 2003 e consultor ad hoc da CAPES e parecerista ad hoc de seleção e avaliação de periódicos da coleção Scielo Brasil. Membro do GT Estudos Bakhtinianos da ANPOLL, membro do Conselho Consultivo do Centro de Educação e Comunicação - UCPEL. Além disso, é secretário do Comitê de Ética em Pesquisa - CEP/UCPEL, membro pesquisador do Grupo de Estudos Semióticos da USP (GES-USP) e do Grupo Tessitura: Vozes em (Dis)curso, da PUC-RS . Líder do Grupo LEAL - Laboratório de Estudos Avançados de Linguagens (UCPEL-RS)

Sobre a entrevista: Resgatando a natureza do diálogo a partir do Círculo de Bakhtin, Adail Sobral traz reflexões que apontam para as especificidades deste termo no referido contexto teórico. A partir da tessitura dialógica em que se entrecruzam vozes, sujeitos, discursos e textos, ele imprime contribuições valiosas concernentes a atualizações e debates pertinentes ao estado atual das pesquisas no campo dos Estudos da Linguagem. Obtida através da interação por e-mails, a entrevista está estruturada a partir dos seguintes eixos: 1) Formação e experiência com a teoria; 2) Sujeito e linguagem em Bakhtin; 3) Estado da arte; 4) Especificidades e contribuições da teoria bakhtiniana; 5) O Círculo Bakhtiniano e a escola e; 6) Ciência da Linguagem na rede. Assim organizada, o diálogo estabelecido com o entrevistado visa contemplar temáticas que venham ao encontro da necessidade contemporânea de discussões que busquem articular a teoria à prática. Dessa forma, a pretendida articulação está proposta a partir das visões de um dos autores mais reconhecidos no âmbito dos estudos do Círculo de Bakhtin na atualidade. Em razão disso, a partir de sua experiência o entrevistado lança luzes sobre o estado atual da teoria bakhtiniana e contempla alguns dos elementos centrais, como sujeito, linguagem e gêneros discursivos. Ao final, Sobral faz um 
balanço das contribuições e (des)encontros da referida teoria com a escola e com a vida. Como não poderia deixar de ser, Adail Sobral também é convidado a nos esclarecer o seu ponto de vista acerca das implicações oriundas da utilização de novas tecnologias, sobretudo no âmbito em que os elementos técnicos e tecnológicos nos possibilitam espaço "inusitados" de interação pela linguagem.

\section{1)Formação e experiência com a teoria}

1.1)SILVEIRA \& CAMPOS: Inicialmente, nos interessa saber como foi a sua aproximação com a teoria e quais deslocamentos o senhor sentiu necessidade de operar nessa mesma teoria em suas análises, sobretudo considerando o princípio bakhtiniano de que somos sujeitos afetados pelo olhar do outro. Especificamente, gostaríamos que comentasse um pouco sobre o que mudou desde o início desse encontro até agora e quais os instantes em que, no contato com a teoria, alguns fatos requereram sua atenção, seja em relação a algum evento relacionado à pesquisa, ou à sua formação, de modo geral.

Adail Sobral: Percorri na graduação em Letras, que conclui em 1977, uma gama de estudos linguísticos, que foram da Filologia Românica a estudos chomskyanos e à Sociolinguística, passando por estudos do André Martinet, Eric Buysens e Peirce, bem como, no campo literário, afora os clássicos mais antigos, Roland Barthes. Na minha época, a formação em Letras não distinguia formação para ensino, para tradução e para pesquisador; era uma formação geral linguístico-literário (lemos todo o livro sobre os formalistas russos), que inclusive exigia nas provas verdadeiros ensaios, escritos em sala de aula.

Fui monitor de teoria gerativa, e já então fiz pesquisa (sobre a negação em português). Também participei do projeto NURC, dirigido em Salvador pelo saudoso Nélson Rossi (recém-falecido aos 86 anos). A sociolinguística e a semiótica me fascinaram, ao trazer a ideia de variação e de sentido (não significado). E foi via sociolinguística que conheci o livro de Marcellesi e Gardin, Introdução à Sociolinguística. Este livro deu início à minha aproximação da teoria bakhtiniana, pois menciona em 1974, três anos antes da publicação, do livro de Voloshinov, Marxismo e Filosofia da Linguagem. Em 1978, entrei no mestrado (afinal não concluído) do IEL da UNICAMP. Lá, tive acesso à edição argentina, da Nueva Visión, desse livro, mais apropriadamente intitulada El signo ideológico y la filosofia del lenguaje. Vi ali, especialmente, duas coisas vitais.

De um lado, um tratamento proveitoso da ideologia que (1) não a reduzia a conteúdos subjacentes à linguagem; (2) não a identificava com o discurso, (3) não a explicava buscando nas marcas linguísticas uma associação automática com essa ou aquela posição do sujeito; (4) não a via como "falsa consciência" nem "visão de mundo"; nem seguindo basicamente os pontos de vista althusserianos, como (5) explicação racional da ordem existente. E, do outro lado, um tratamento da linguagem, a 
partir da sintaxe, em termos das formas de presença do sujeito em seus enunciados, algo que se pode denominar uma "sintaxe da enunciação".

O resgate do sujeito do sistema linguístico, ao lado de sua "dessubmissão" de um ideológico todo-poderoso e da demonstração de que a análise da língua podia ser análise da linguagem, por assim dizer, mostraram-me o que havia de insatisfatório para mim nas tantas teorias com que eu tivera contato. A meu ver, esse contato com a linguística formal e a não formal era suficiente para vê-las criticamente, e para argumentar em favor de uma perspectiva que as combinasse com ênfase no sujeito, em sua "construção do mundo" via linguagem, e seu agir, e não só em termos linguísticos estritos.

Minha dissertação (na época não defendida, porque não concordei com as propostas da banca e desisti), teve sua versão final terminada em 1983. Ela se propunha a redefinir a noção de "lugar social", então em voga, especialmente junto a quem trabalhava com Michel Pêcheux, em termos das teorizações de Voloshinov. Na época eu já tomara contato também com a "teoria do romance" e com o Rabelais, ambos em edição francesa. E tudo isso teve uma influência no que eu viria a fazer.

Depois de desistir de defender a dissertação, saí da academia, e dediquei-me a traduzir, ler e viajar. Esse "descanso" das exigências acadêmicas, que durou 15 (!) anos, não me prejudicou em nada. Pelo contrário, o que li e traduzi ao longo desse período abriu ainda mais meus horizontes. Quando voltei, certas coisas que eu tinha vislumbrado sem poder definir com o rigor que mereciam, e/ou sem a capacidade de negociação que a academia requeria, já se tinham tornado aceitas ou ao menos consideradas.

Nesse período, não me afastei de Bakhtin e colegas, e li e traduzi vários outros autores: Lacan, Freud, vários outros filósofos, como Bachelard, Merleau-Ponty, Hegel, Kant, Heidegger, Humboldt, Aristóteles, Darwin, Leibniz etc. Também traduzi textos de vários filósofos (Baudrillard e Guattari, p. ex.) e sobre vários filósofos antigos e modernos e muitos outros textos. Em tudo isso estava presente o filósofo Bakhtin e o olhar com que eu o lia já não era o mesmo: o filosófico se sobrepôs ao linguístico, com o passar do tempo. E, traduzindo, passei a ver com mais clareza que a forma do conteúdo e a forma da expressão (Hjelmslev), unidas, davam conta do sentido, desde que consideradas não só na imanência como na prática do uso da língua.

Dessa forma, compreendi também que Bakhtin e colegas davam a melhor resposta a questões que me preocupavam: o que é ser sujeito, a relação entre o linguístico e o discursivo, e entre sujeito empírico e sujeito de discurso; entre ética e pesquisa; entre marcas linguísticas (elementos do sistema da língua que constituem frases) e marcas enunciativas (marcas da transformação de frases - sistema da língua em enunciados - sistema de uso da língua). Tive de recorrer, nas minhas pesquisas, a exteriores teóricos (Maingueneau; Greimas; Hjelmslev; Benveniste), porque meus objetos assim o requeriam.

É preciso assinalar que toda teoria linguística traz embutida alguma concepção filosófica (Chomsky reconheceu o papel de Humboldt na sua, por exemplo), mas em geral não há o reconhecimento disso: alguns querem atribuir a suas propostas um caráter "neutro", como se o linguístico não fosse apenas um componente de algo mais amplo, 
qual seja a identidade dos sujeitos humanos, em interação, na sociedade e na história. Toda teoria filosófica traz em si alguma concepção de ser humano e de linguagem. Mas, em geral, não há uma conciliação entre uma coisa e outra. No caso de Bakhtin, e, em menor medida, por razões específicas, de Voloshinov e Medviedev, vemos um esforço de elaboração do que se poderia chamar de teoria da simbolização discursiva $e$ identitária, ou de como o ser humano se constitui na coletividade e em seu psiquismo, em todas as suas atividades dialógicas, incluindo o uso da linguagem, mas sem restringir-se a ele.

A partir de meu contato com a filosofia do ato de Bakhtin (durante o doutorado, no LAEL, da PUC-SP), que mostra o vínculo entre as várias propostas, constituindo de fato uma filosofia dialógica, julgo poder dizer que houve em minha atividade de pesquisa duas mudanças vitais que creio que hoje estão se unindo: de um lado, a necessidade imperiosa de ir ao texto e entender seu funcionamento em língua, isto é, segundo o sistema linguístico, e como exemplar de algum conjunto de regras de coesão e coerência que cria textualidade, de outro, a necessidade imperiosa de considerar o contexto (que envolve sujeitos, tempo, lugar, conjuntura, possibilidades de ação) para entender o funcionamento do texto em contexto.

Finalmente, cabe acentuar que se não entendo a álgebra da língua nem conheço as formas de organização de textos, não posso entender um texto. Mas se entendo tudo isso e não conheço as restrições, ou coerções, que o contexto estabelece, também não posso entender o texto. $\mathrm{O}$ sentido de um texto nasce de um sistema complexo chamado linguagem; esse sistema é formado por dois outros sistemas, um menos aberto, o sistema da língua e outro mais aberto, o sistema de uso.

\section{2)Sujeito e linguagem em Bakhtin}

2.1)SILVEIRA \& CAMPOS: Sabemos que sujeito e linguagem são dois conceitos caros aos estudos linguísticos contemporâneos, sobretudo porque demarcam o espaço epistemológico das teorias que operam sob o viés discursivo. Desse modo, parece-nos inevitável iniciar essa entrevista perguntando: qual a relação entre sujeito e linguagem que pode ser depreendida no interior dos estudos do Círculo de Bakhtin?

Adail Sobral: Resumi isso em Do dialogismo ao gênero mais ou menos assim: se o autor [sujeito] empírico dos discursos [para distinguir de enunciado no sentido linguístico estrito] cria a si mesmo como autor de papel [ou de som] nos discursos, o sujeito humano [que ele é] se cria e se recria a si mesmo no mundo, mas de forma alguma é autor do mundo, o que nem por isso faz dele uma mera peça numa suposta engrenagem social e histórica, mas o membro de uma corrente dialógica que lhe permite apropriar-se da linguagem e criar enunciados únicos e irrepetíveis que são compreensíveis por partilharem com outros certas características, como elementos repetíveis da língua que assumem sentidos únicos em linguagem.

Neste sentido, podemos dizer que Bakhtin propõe como a "tarefa" do sujeito ir até o outro (ser eu-para-o-outro). Mas fazê-lo só é positivo se este sujeito se voltar para 
si mesmo (ser eu-para-si) depois de mostrar ao outro o que ele não pode ver sozinho e depois de ter visto o outro mostrando-nos o que não podemos ver sozinhos. Dessa forma, dois pontos de vista (ao menos), duas consciências imiscíveis, afastam-se do isolamento negativo quando vão ao encontro do(s) outro(s), não necessariamente para se compatibilizarem, mas para conhecerem o que os distingue e, assim, se o desejarem, criarem um terceiro ponto ou alterar os seus de alguma maneira. O sujeito é individual, eu-para-si, e é relacional, eu-para-o-outro, e cria a totalidade de si mesmo, sempre instável, a partir dos atos isolados de si que vêm dos outros (cada um de uma maneira!).

Contrariando uma literatura sobre identidade (ou sobre o sujeito) que busca salvaguardar uma idealística "inocência" de um pobre sujeito subjugado, propondo para ele álibis espúrios, ou que fazem do sujeito um senhor absoluto de sua existência, o filósofo Bakhtin reconhece a "determinidade" de todos nós, as coerções que nos atingem, mas defende intransigentemente nossa responsabilidade, porque tomar consciência de sua determinidade e tentar (apesar e/ou por causa dela) dar sua própria versão de como agir nesse âmbito é que faz do ser humano um ser livre - na medida de suas possibilidades conjunturais - em meio a restrições à sua liberdade. Isso ocorre tanto ontológica como discursivamente.

Neste contexto, as principais implicações da concepção de sujeito de Bakhtin são a meu ver: (a) o sujeito age mediante a linguagem numa situação concreta organizada em torno de práticas sociais e históricas que limitam as possibilidades de atos e de formas de realização de atos e (b) essas circunstâncias específicas devem ser consideradas em todo entendimento de atos; (c) em meio a essas restrições, o agir de cada sujeito é único, propriedade e responsabilidade de cada sujeito.

As práticas sociais, vinculadas com as esferas de atividade, supõem necessariamente grupos humanos, e não sujeitos isolados; situações concretas e sujeitos concretos. Supõem ainda a intencionalidade do sujeito de realizar atos e sua realização concreta de acordo com formas aceitas de realização, mesmo nos casos em que uma sucessão de atos, seguindo essas normas, desemboca na alteração delas (o aspecto estático-dinâmico de todo agir humano). Trata-se de um estranho equilíbrio entre o mesmo e o novo, entre estabilidade do estabelecido e alteração do processo de mobilização desse estabelecido: o sistema da língua e o sistema dos atos sociais são mobilizados pelo processo de enunciação e pelo processo de ação, que ocorrem em contextos concretos que permitem aos sujeitos dar sua própria versão do "mesmo", ou seja, criar um "outro". Assim, os outros nos ajudam a sermos mais os seres que podemos nos tornar para sermos cada vez mais completos, mas nunca com uma teleologia fixa: estamos sempre nos completando (o ipse de Ricoeur, eu-para-si, os aspectos que vamos incorporando em nossas vivências), ainda que sempre com aspectos individuais que não se alteram (o idem de Ricoeur, eu-para-o-outro, o que dá conta daquilo que sentimos ser nosso eu).

Dessa forma, os sujeitos são um constante tornar-se e não torna-se seres fixos. Somos sujeitos porque sempre nos tornamos sujeitos - e o sujeito que cada um de nós é, não outro. Somos não terminados e intermináveis. Não há a identidade como algo fixo, mas apenas modos individuais de identificação. Cada sujeito é sujeito à sua própria maneira, que muda de acordo com os diferentes outros com que ele se relaciona. 
Adquirimos subjetividade ao nos envolvermos cada vez mais em relações com novas pessoas. Adquirimos porque cada relação nos traz novos fragmentos sobre nós mesmos, e os usamos para sermos mais o que somos, ou melhor, o que somos capazes de nos tornar.

\section{3)Estado da arte}

\section{1)SILVEIRA \& CAMPOS: Considerando, sobretudo, o cenário nacional, o que pode ou deve ser destacado sobre o atual estado da arte das pesquisas filiadas ao Círculo bakhtiniano?}

Adail Sobral: Hoje, creio que estamos superando o que chamei de visão ingênua do dialogismo, que busca sempre excluir o desacordo do dialógico. No âmbito do dialogismo, sabe-se hoje, o desacordo não se exclui, mas é parte constitutiva: só há sentido porque há desacordo, diferença. Tudo é dialógico para a concepção dialógica, exceto a quebra do diálogo, como a morte, o assassinato, o afastamento total e absoluto (se é que este existe, uma vez que se vão as pessoas e ficam as ideias). O silêncio ainda é uma resposta; o silenciamento também, embora este impeça a réplica do outro e quebre a continuidade, o que lhe tira o caráter dialógico. Analiticamente, o silenciamento impede a emissão da voz, mas não a apaga.

Dialógico não é sinônimo de amor universal, total e absoluto, nem monológico implica a presença de uma voz única, ainda que só se ouça uma. A manutenção de duas posições contrárias em confronto é dialógica. O que pode haver de incoerente é alguém se dizer disposto a considerar a posição do outro e ser intransigente a ponto de considerar sua vontade como o único fator relevante, sem examinar as escalas axiológicas relativas em confronto na situação. Incoerente, mas não necessariamente não-dialógico, desde que ela não busque impor essa sua vontade!

Infelizmente, entre pessoas que trabalham com as teses do Círculo há intolerância, e até fundamentalismo, o que é a meu ver uma contradição, pois isso implica que ser dialógico é concordar; mas sempre são uns que devem concordar e só alguns propõem aquilo com que se concordar. Há também quase um "culto" de Bakhtin. Mas isso é coisa de uma minoria que não entendeu, ou não quis entender, que dialogismo é uma teoria filosófica da linguagem e não uma crença ou programa de partido. Sabe-se também hoje que toda escuta é alteritária, porque envolve sempre o outro, mas pode ser autoritária, ao tentar estabelecer o que o outro pode dizer a ponto de deixar implícito que só se escutará o esperado e jamais o inusitado.

O dialogismo talvez sirva, sem fundamentalismos, também para pensar questões extralinguísticas como: diante de um confronto, que valores devem/podem prevalecer num dado momento e lugar? Os de uma das posições? Os da outra? Um misto dessas posições? Uma outra posição negociada? Algum valor mais amplo que esteja além das duas posições? Será que há valores universais, como o que justifica o repúdio a toda tentativa de impor coisas ao outro, como por exemplo a circuncisão feminina? Não há razões para recusar sempre o massacre, a carnificina, a imposição de um poder arbitrário que leve ao sofrimento e à morte? Por isso é vital saber que hoje estamos 
tendo sucesso em combater a visão ingênua de dialogismo, que pode fazer parecer que diálogo é harmonia universal e/ou aceitação do inaceitável em nome de respeitar o outro. Ou que acha que dialogismo é uma crença ou programa de partido.

É possível entender-se sem concordar com o outro, bem como tomar posição em questões práticas, a partir do dialogismo, o que hoje já vem acontecendo, apesar de por vezes de modo fanático. Mas isso requer um trabalho, não simplificações que dizem que, se discordo, não estou sendo dialógico ou que assumem posições fundamentalistas, como "sou bakhtiniano, logo sou melhor". Aliás, não sou bakhtiniano; sou adailiano: trabalho com teses de Bakhtin e colegas, ao lado do que for necessário de teorias, e dou a minha versão, que assumo sem álibi. Hoje quem estuda Bakhtin no mundo prefere ser chamado de bakhtinista, o que nos situa como estudiosos, e não seguidores.

Fico animado por ver que hoje o dialogismo tem reconhecidos sua amplitude e potencial heurístico, por ver seus fundamentos servindo de base a distintos trabalhos que partem de seus parâmetros e constroem, tirando proveito de sua flexibilidade, suas próprias metodologias, assimilando a ideia do dialogismo da irrepetibilidade como a marca do enunciado, em meio aos aspectos repetíveis de seu instrumento, as linguagens. Na Europa, já se fala de "Escola Brasileira" de bakhtinistas, como ocorreu na mais recente Bakhtin Conference, onde tive aprovados um simpósio e uma comunicação individual. Por outro lado, há iniciativas de várias áreas em trabalhar com as teses de Bakhtin e Círculo mediante sua apropriação, assimilação e ressignificação, em situações de ensino (parte dos membros do GT de Estudos Bakhtinianos da ANPOLL está dando atenção a isso), de uso de tecnologias da informação e comunicação, de análise de fenômenos culturais diversos (como o carnaval), na mediação intersetorial etc.

\section{4)Especificidades e contribuições da teoria bakhtiniana}

4.1)SILVEIRA \& CAMPOS: O quadro dos conceitos que podem ser mobilizados em análises que se filiem ao círculo bakhtiniano é relativamente extenso. Naturalmente, como acontece nas diversas correntes teóricas, é comum associarmos alguns conceitos que, no cotejo entre um e outro, podemos alçar as análises a empreendimentos mais significativos, não só do ponto de vista acadêmico, mas do próprio resultado a que se pretende chegar, quando o pesquisador se dispõe a determinados objetivos de pesquisa. Assim considerados, gostaríamos que discorresse sobre quais as relações que podemos estabelecer entre os pares "linguagem e sociedade", "discurso e língua", "enunciado, gênero e discurso" a partir dos estudos bakhtinianos?

Adail Sobral: Vou falar disso sem mencionar os pares e/ou tríades, mas do ponto de vista epistemológico: de onde vêm esses conceitos e como trabalhar com eles. As relações entre os pares e tríades mencionados já foram abordadas por mim em vários textos, e não houve mudança de opinião. Num dado momento, passei a ver com mais clareza que a forma do conteúdo e a forma da expressão (para usar Hjelmslev), unidas, davam conta de parte da organização dos discursos e que, com isso, se poderia chegar 
ao sentido, desde que a relação entre elas fossem consideradas de acordo com a prática do uso da língua (das linguagens).

Compreendi então que Bakhtin e colegas davam a melhor resposta a questões que me preocupavam: a relação entre o linguístico e o discursivo, entre sujeito empírico e sujeito de discurso; entre ética e pesquisa; entre marcas linguísticas (elementos do sistema da língua que constituem frases) e marcas enunciativas (marcas da transformação de frases - sistema da língua - em enunciados - sistema de uso da língua). Cabe destacar que Bakhtin e seus colegas tinham interesses específicos, de sua época, e nós temos outras questões, específicas, de nossa época, bem como outros interesses e objetos. Não posso aplicar Bakhtin; mas posso pensar a partir de Bakhtin, e recorrer ao que me ajude em minha tarefa, desde que meu trabalho compatibilize os exteriores teóricos com Bakhtin. Isso não vai "conspurcar" o "Santo Bakhtin". É vital, contudo, que se atente para os possíveis pontos de convergência: não posso falar de diálogo e usar Bakhtin e Freire sem considerar suas diferenças epistemológicas e suas eventuais semelhanças. Tenho de mostrar isso e não pressupor que, se os dois falaram de "diálogo", o sentido é o mesmo.

É extremamente importante ter consciência de que a teoria dialógica não é só linguístico-discursivo-genérica, mas também uma teoria filosófica do ser-no-mundo, da subjetividade, da responsabilidade ética; não apenas uma teoria da enunciação, mas uma filosofia do processo e da vida. Também não é uma doutrina nem um programa partidário, mas é bem mais do que uma teoria da linguagem. Devemos, contudo, ter cuidado para não julgá-la capaz de resolver problemas para os quais ela não foi proposta.

A teoria dialógica sempre vê um texto como um aparato técnico de realização das necessidades de um gênero a partir de relações enunciativas, que têm caráter discursivo, fruto da interação entre sujeitos, na presença ou na ausência. O texto se constrói mediante as formas de enunciação conjunturalmente possíveis em algum hic et nunc, ou seja, segundo as discursividades vigentes, sempre de acordo com as necessidades dos gêneros. Neste âmbito, o gênero é uma forma social e historicamente organizada de realizar atos e atividades de caráter linguístico.

A partir disso, posso dizer que houve em minha atividade de pesquisa duas mudanças vitais que creio que hoje estão se unindo: de um lado, a necessidade imperiosa de ir ao texto e entender seu funcionamento em língua, isto é, segundo o sistema linguístico, e como exemplar de algum conjunto de regras de coesão e coerência que cria textualidade. De outro, a necessidade imperiosa de considerar o contexto (que envolve sujeitos, tempo, lugar, conjuntura, possibilidades de ação) para entender o funcionamento do texto em contexto. Como afirmei em uma questão anterior, "se não entendo a álgebra da língua nem conheço formas de organização de textos, não posso entender um texto". Se entendo tudo isso, mas não conheço as restrições, ou coerções, que o contexto estabelece, também não posso entender o texto. $\mathrm{O}$ sentido de um texto nasce de um sistema complexo chamado linguagem; esse sistema é formado por dois outros sistemas, um menos aberto, o sistema da língua e outro mais aberto, o sistema de uso. 


\section{5)O Círculo Bakhtiniano e a escola}

5.1)SILVEIRA \& CAMPOS: Pensamos ser importante destacar o avanço que determinados posicionamentos teóricos, no campo dos estudos da linguagem, trouxeram para a prática de ensino de línguas, sobretudo aqueles que incidem sobre a noção de texto, atualmente, objeto privilegiado nos processos de ensino e de aprendizagem. Em sua opinião, de que forma os estudos bakhtinianos contribuem para as atividades de produção e análise de textos? $\mathrm{E}$, precisamente, qual/quais o(s) ganho(s) trazido(s) pela teoria para a formação do professor de línguas?

Adail Sobral: Não tenho visto muita influência dos estudos bakhtinianos na prática do ensino de línguas, nem na produção e análise de textos, apesar de muitas alegações de que sim e de pesquisas sérias que infelizmente não chegam à escola. Creio que isso vai acontecer com o tempo, à medida que formarmos mais pessoas que tomam conhecimento das teorias bakhtinianas e podem vir a ser formadoras, e à medida que se vá criando uma mentalidade propícia ao ingresso dessas teorias na escola. Uma coisa são pesquisas na academia; outra é a chegada delas à escola.

Vejo muitas afirmações sobre isso e conheço pesquisas que tentam fazer Bakhtin chegar à escola, mas nas escolas de modo geral ainda vejo no máximo iniciativas isoladas. Há também umas poucas obras didáticas que avançam nesse sentido. Mas há exceções. Merecem menção, como iniciativas que estão levando as concepções bakhtinianas à escola, o GEPEC, da UNICAMP, e o LEDUC, da UFRJ. Esses grupos de pesquisa dão a termos como "dialógico" e "alteritário", substantivados, um novo sentido adjetivado (como diz Rosaura Soligo, membro do GEPEC), que advém da exploração sistemática da ideia da interconstituição eu-outro do dialogismo, e da ideia de escuta alteritária como esforço de ir de fato até o outro e escutá-lo de fato, em vez de apenas ouvir e interpretar o dito de algum modo que desconsidere quem disse e como disse.

5.2)SILVEIRA \& CAMPOS: O professor e pesquisador Wanderley Geraldi criticou, em $A$ aula como acontecimento, a escolarização do estudo dos gêneros discursivos, estes que, segundo ele, passaram a ser "adestrados em práticas que buscam estabilizar o que não é estabilizável", já que estão intimamente ligados às práticas de linguagem de que derivam, portanto, sujeitos a serem relativamente estáveis, como bem nos ensinou Mikhail Bakhtin, em sua Estética da criação verbal. Qual a sua opinião sobre o ensino de gêneros discursivos nas escolas?

Adail Sobral: Concordo com o Geraldi, e, em outros termos, faz uns 10 anos que venho dizendo isso. Em geral, embora haja (raríssimas) exceções, o que chega à escola são diluições do conceito de gênero de Bakhtin, sua redução a uma técnica de interpretação de textos desfocada, descontextualizada. Gênero se torna aí um conteúdo de ensino e, passa a ser transmitido como conteúdo estático. Isso leva a propostas que dizem, por exemplo, "o gênero biografia narra eventos significativos de uma vida" O primeiro erro: não existe um gênero "biografia", mas vários gêneros biografia, mesmo que o texto em si seja similar. O que marca um gênero é o projeto enunciativo, a posição do sujeito que 
diz. Tema, estilo e forma de composição são só meios técnicos, e, sem se considerar o projeto enunciativo, pouco importam. O segundo erro: trabalham-se gêneros como se fossem textos, ou tipos de texto; por isso se fala de "gênero dissertativo-argumentativo", que não é um gênero, mas uma forma de textualização específica que pode estar em vários gêneros.

Embora parte disso se deva a certa confusão conceitual dos PCNs, isso também se deve a uma concepção de ensino vigente do país: o ensino transmissivo, aquele em que o professor transmite um conteúdo ao aluno, entendendo-se esse conteúdo como algo fixo que é transmissível. Gênero não é conteúdo, mas um modo de ver os textos em seus contextos. Todo ensino supõe transposição, modelização, ou seja, simular o objeto de fora da escola dentro dela; isso é inevitável, porque não é possível trazer tudo diretamente para o aluno. A modelização é mais necessária nas séries iniciais, e vai, idealmente, se reduzindo. Quando a modelização se enrijece e torna o objeto estático, temos um fracasso que perturba o ensino e, com ele, a aprendizagem, transmitem-se modelos e não os objetos a que se referem os modelos. Num trecho dos PCNs é dito que os gêneros são modelos! Aí acaba o ensino e começa a transmissão, que destrói o objeto e a aprendizagem. Acho que em geral é assim que se trabalha com gêneros: como modelos de texto, entendidos como tipos de texto (os PCNs também dizem isso!), o que nada tem de gênero. É trabalhar com narração, descrição ou dissertação dizendo que se trabalha com gêneros.

Julgo necessário um trabalho que veja de fato os gêneros como formas ou tipos relativamente estáveis de enunciados/discursos que têm uma lógica própria, de caráter concreto, e recorrem a certos tipos estáveis de textualização (tipos de frases e de organizações frasais mobilizadas costumeiramente pelos enunciados de certos gêneros), mas não necessariamente a textualizações estáveis (frases e organizações frasais que sempre se repitam), pois são tipos ou formas de enunciados (o que cobre o aspecto formal e não formal dos gêneros). Gêneros são formas de interlocução vinculadas a esferas de atividade, onde ocorre a produção, circulação e recepção de discursos, definindo-se através da forma de composição, do tema e do estilo, mas mobilizados pelo projeto enunciativo, estando este vinculado com uma dada arquitetônica. Essa perspectiva é claramente mais ampla do que certas propostas de trabalho com gêneros, que são demasiado textuais para trazer alguma novidade, havendo algumas que destroem o contexto ao reduzi-lo a uma intenção comunicativa nunca definida em termos de relações sociais e práticas discursivas.

De modo geral, numa análise, devemos fazer "perguntas" aos exemplares de gênero. Essas perguntas abordam (1) as condições em que os gêneros são produzidos e recebidos e nas quais circulam e que tipo de locutor os produz para que interlocutores; e (2) as características textuais e composicionais desses exemplares, que podem estar presentes em tantos outros. Em outras palavras, cabe cobrir os aspectos textuais mais estritos e os aspectos enunciativos mais amplos, porque um gênero é composto por um texto inserido de uma dada maneira num contexto por um locutor que se dirige a um dado interlocutor. Não se deve procurar isolar tema, estilo e forma de composição, que estão intimamente ligados, mas ver o texto a partir dessas categorias considerando o projeto enunciativo, a produção, a circulação e a recepção. Essas perguntas devem ser 
adequadas ao nível dos alunos com os quais se trabalha usando os gêneros, e talvez isso constitua um problema adicional: como "traduzir" o conceito para diferentes interlocutores-alunos.

5.3)SILVEIRA \& CAMPOS: Fala-se cada vez mais nos distanciamentos entre estudantes e ambientes escolarizados. Sob o viés da crítica que emerge das mídias, por exemplo, a escola muitas vezes é apresentada como defasada, caso consideremos os avanços decorrentes das novas tecnologias. Gostaríamos de convidá-lo a posicionar-se nessa discussão, considerando, principalmente, sua compreensão do conceito de alteridade, para nós, tão caro a uma análise que se pretenda vinculada aos estudos bakhtinianos, sobre a relação entre as novas tecnologias e as "novas" formas de interação pela linguagem.

Adail Sobral: As linguagens são dinamismos estáveis, com variados graus de dinamismo e estabilidade combinados. Dispõem de um sistema estruturado de componentes e regras de combinação desses componentes. E dispõem de um sistema de interlocução que cria sentidos contextualmente. Este último sistema é o que mais nos interessa. Embora as linguagens tenham formas distintas de criar as significações em seu sistema de componentes e de criar sentidos em seu sistema de uso, é neste último que surgem os sentidos, e isso supõe um quadro enunciativo: um locutor, interlocutores, um contexto social e histórico, formas de produção, circulação e recepção de enunciados. Esse quadro enunciativo influencia as formas de interlocução que se manifestam.

O ambiente em que se usa a linguagem condiciona, por exemplo, a leitura, mas o principal condicionante é a motivação da leitura: o que quero ao ler? Se leio para estudar algo, para obter informações ou para resolver uma questão de pesquisa, farei leituras distintas, abordarei diferentemente o mesmo texto. Um texto impresso facilita a vida do leitor porque ele pode virar as páginas com facilidade; um texto digital facilita a vida do leitor porque ele pode fazer buscas e copiar com facilidade.

No primeiro caso, não posso fazer buscas e copiar com facilidade; no segundo, não posso virar a página (mesmo os aparelhos que simulam isso não equivalem a esse virar a página, porque falta a sensação tátil). Contudo, nos dois casos, o que se sobrepõe é a intencionalidade da leitura: se leio para aprender algo, minha relação com o texto não é a mesma de minha leitura superficial só para ver que frase foi dita por alguém num dado momento.

Sim, a escola deve usar tecnologia, mas sabendo que, com ou sem ela, o importante é a concepção de ensino, o que inclui saber quem é o aluno, em vez de supor que ele é conhecido. Todos na escola deveriam ao menos conhecer a tecnologia. Não é preciso ser usuário ativo de tudo, mas cabe saber como funciona. O professor que sabe para que serve um recurso pode usar o saber dos alunos em favor do ensino e da aprendizagem.

Houve nos últimos 40 anos uma revolução tecnológica, que foi tendo fases: 1980, 1990, 2000, 2010. Nesta fase mais recente, houve grandes mudanças nos celulares (a tela touch é uma revolução) nos tablets e leitores de ebooks e isso tem de ser 
considerado na escola. A Internet permitiu criar comunidades as mais diversas, as chamadas redes sociais, com base em plataformas como o Facebook. De nada vale reclamar que o aluno não é mais o mesmo, faz tempo que ele mudou! Sim, o aluno mudou. Cabe ver que aluno é e trabalhar com ele. Na verdade, ver que alunos são, e acho que aí entra a ideia da alteridade. Não deve nos importar a turma de alunos per se, como algo impessoal em que se diluem todas as diferenças individuais, mas cada aluno da turma, em sua individualidade, por vezes incômoda, mas com a qual temos de lidar, como profissionais responsáveis perante as novas gerações e pelas nossas escolhas.

As formas de interação criadas na Internet, em sua variedade, permitem o inimaginável até recentemente. Hoje posso falar em 20 minutos com uma pessoa de cada estado brasileiro; posso chegar ao ponto de ir a qualquer capital, por exemplo, e encontrar algum amigo do Facebook que nunca vi antes, mas com quem falo virtualmente. A interação dita virtual não produz isolamento, podendo mesmo facilitála, levando as pessoas a querer conhecer seus amigos virtuais. Claro que não falo de casos patológicos, mas esses não dependem da realidade virtual para se manifestarem. Nada há de estranho em estarem pessoas de uma família juntas cada qual com seu celular, a não ser que essa seja a única forma de contato sua.

Dessa forma, na escola, obviamente, não se pode atentar para a aula e usar o celular - a não ser que ele possa ser usado para a aula. Os professores devem tirar proveito da existência dos recursos e da capacidade de uso dos alunos, tornando as aulas mais dinâmicas. Esses recursos ajudam a tornar o aluno mais ativo, a ser protagonista de sua aprendizagem; eles libertam os professores da tarefa de transmitir conteúdos e permitem que eles se tornem organizadores do ensino e promotores da aprendizagem, inclusive ajudando os alunos a aprender a filtrar a multiplicidade de informações que circula no mundo virtual.

\section{6)Ciência da Linguagem na rede}

6.1)SILVEIRA \& CAMPOS: Recentemente, acompanhamos uma postagem sua numa rede social na qual discorria sobre o fato de muitos considerarem ingenuamente, que o "[...] dialogismo sempre [exclui] o desacordo". Gostaríamos de ouvi-lo sobre essa afirmação e perguntar: qual é a sua visão sobre o papel desse tipo de discussão nas redes sociais?

Adail Sobral: Falei um pouco disso acima, e agora falarei sobre isso. Essa questão da visão ingênua tem duas faces. Temos de combatê-la porque ela parece dizer que, segundo a concepção dialógica, o mundo é harmônico, sem tensões, e que, se somos "dialógicos", concordamos com tudo ou em tudo uns com o outros. Isso gera coisas do tipo: "ele discordou; logo, não foi dialógico!"; “ele concordou; como é dialógico!”. Ora, a filosofia bakhtiniana não é idealista; ela afirma que o diálogo é marcado pela tensão, que é uma "arena de vozes", logo, um lugar de negociação, que pode ser difícil.

Neste contexto, para exemplificar, se um aluno diz que minha aula é ruim, tenho de ver com ele em que é ruim e, se for o caso, mudá-la. No processo, vou aceitar umas coisas e recusar outras. Isso é dialogismo, é diálogo. Não vou impor nem deixar que o 
aluno imponha. Considero o outro, o ponto de vista do outro, mas ninguém será obrigado a concordar com o outro. Dialogismo é tensão; é ver o ponto de vista do outro com respeito, mas sem a obrigação de aceitá-lo. É tentar o acordo em meio a divergências. Bakhtin diz mesmo que estamos "condenados" ao outro, a conviver com ele. Como costumo dizer sobre alguns interlocutores: "não concordamos sempre, mas nos entendemos em nossas divergências" - talvez essa seja minha síntese da questão.

Quanto à outra parte da pergunta, o papel desse tipo de discussão nas redes sociais é trazer para a vida questões que não deveriam ficar restritas à academia. $\mathrm{E}$ acaba por mostrar que rede social é lugar em que se formam laços e se compartilham ideias, em que se debatem tópicos de interesse de ao menos duas pessoas. Isso mostra ainda que a Internet não é apenas entretenimento, e que, nela, é possível fazer as mais diversas coisas. Além disso, quando, antes das plataformas de redes sociais, foi possível discutir teorias e política, quase sincronicamente, com pessoas de 5, 10, 20 cidades distintas, de formações distintas, de opiniões políticas distintas?

Temos de usar, para nossos fins pessoais e profissionais, os recursos disponíveis. Se a Internet é um deles, e potente, por que não usá-la? Isso não é algo restrito à escola, à pesquisa, mas tem que ver com a vida, com a participação política na vida concreta. Não falo de partidos, mas de tomar posição em aspectos relevantes da vida; na aula, nas plataformas que abrigam as redes sociais, nas relações pessoais de todos os tipos, na ética da pesquisa. A visão ingênua de dialogismo pode ser manipulada para nos impor opiniões alheias, de grupos ou instituições, e nos cobrar a aceitação do inaceitável em nome da dialogia, da harmonia etc. Esse é outro motivo de discutir dialogismo na rede e discutir a rede e outros objetos a partir do dialogismo.

\section{Referências:}

BAKHTIN, M.M. Estética da criação verbal. $6^{\text {a }}$ ed. Tradução do russo: Paulo Bezerra. São Paulo: Martins Fontes, 2011.

BAKHTIN, M.M. Hacia una filosofia del acto ético: de los borradores y otros escritos. Tradução e notas: Tatiana Bubnova. Barcelona: Anthropos; San Juan: EDUPR, 1997.

BAKHTIN, M.M. Para uma filosofia do ato responsável. São Paulo: Pedro \& João editores, 2012.

BAKHTIN, M.M. Questões de literatura e estética (Teoria do Romance). $3^{\text {a }}$ ed. Tradução: A. F. Bernadini et. al. São Paulo: UNESP, 1993.

BAKHTINE, M. L'oeuvre dde François Rabelais et la culture populaire au Moyen Age et sous la Renaissance. Tradução: Andrée Robel. Paris: Galimard, 1970.

GERALDI, João Wanderley. A aula como acontecimento. São Paulo: Pedro \& João editores, 2010.

MARCELLESI, J.B.; GARDIN, B. Introdução à Sociolinguística. Lisboa: Editorial Aster, 1975. 
SOBRAL, Adail. Do dialogismo ao gênero: as bases do pensamento de Bakhtin. Campinas: Mercado de Letras, 2009.

VOLOSHINOV, V.N. EI sygno ideológico y la filosofía del language. Tradução: Rosa María Rússovich. Buenos Aires: Nueva Visión, 1976. 